\title{
Game Theory in Molecular Nanosensing System for Rapid Detection of $\mathrm{Hg}^{2+}$ in Aqueous Solutions
}

\author{
Nan Fang $\mathrm{Nie}^{\dagger}{ }^{,}$, Xin Xing Zhang ${ }^{\dagger}$, Chu Shan Fang, Qiu Yan Zhu, Jiao Yang Lu, Fu Rui Zhang, \\ Qing Feng Yao, Wei Tao Huang *D, Xue Zhi Ding and Li Qiu Xia \\ State Key Laboratory of Developmental Biology of Freshwater Fish, Hunan Provincial Key Laboratory of \\ Microbial Molecular Biology, College of Life Science, Hunan Normal University, Changsha 410081, China; \\ N2944626564@163.com (N.F.N.); zxx02215@163.com (X.X.Z.); F745317040@163.com (C.S.F.); \\ 18199765199@163.com (Q.Y.Z.); joyceway@163.com (J.Y.L.); furui912443212@163.com (F.R.Z.); \\ 17136373635@163.com (Q.F.Y.); dingxuezhi@hunnu.edu.cn (X.Z.D.); xialq@hunnu.edu.cn (L.Q.X.) \\ * Correspondence: vthuang@hunnu.edu.cn; Tel.: +86-731-8887-2905 \\ † These authors contributed equally to this work and should be considered co-first authors.
}

Received: 5 November 2018; Accepted: 6 December 2018; Published: 7 December 2018

Abstract: Game theory—the scientific study of interactive, rational decision making-describes the interaction of two or more players from macroscopic organisms to microscopic cellular and subcellular levels. Life based on molecules is the highest and most complex expression of molecular interactions. However, using simple molecules to expand game theory for molecular decision-making remains challenging. Herein, we demonstrate a proof-of-concept molecular game-theoretical system (molecular prisoner's dilemma) that relies on formation of the thymine- $\mathrm{Hg}^{2+}$-thymine hairpin structure specifically induced by $\mathrm{Hg}^{2+}$ and fluorescence quenching and molecular adsorption capacities of cobalt oxyhydroxide $(\mathrm{CoOOH})$ nanosheets, resulting in fluorescence intensity and distribution change of polythymine oligonucleotide 33-repeat thymines (T33). The "bait" molecule, T33, interacted with two molecular players, $\mathrm{CoOOH}$ and $\mathrm{Hg}^{2+}$, in different states (absence $=$ silence and presence $=$ betrayal), regarded as strategies. We created conflicts (sharing or self-interest) of fluorescence distribution of T33, quantifiable in a $2 \times 2$ payoff matrix. In addition, the molecular game-theoretical-system based on $\mathrm{T} 33$ and $\mathrm{CoOOH}$ was used for sensing $\mathrm{Hg}^{2+}$ over the range of 20 to $600 \mathrm{nM}$ with the detection limit of $7.94 \mathrm{nM}(3 \sigma)$ and for determination of $\mathrm{Hg}^{2+}$ in pond water. Inspired by the proof-of-concept for molecular game theory, various molecular decision-making systems could be developed, which would help promote molecular information processing and generating novel molecular intelligent decision systems for environmental monitoring and molecular diagnosis and therapy.

Keywords: cobalt oxyhydroxide nanosheets; fluorescent sensing; game theory; $\mathrm{Hg}^{2+}$; thymine- $\mathrm{Hg}^{2+}$-thymine

\section{Introduction}

Game theory-the mathematical modeling of the strategic interaction between rational decision-makers-describes the interaction of two or more agents (or players), where the payoff for each player is determined not only by their own decision, but also by the strategies adopted by the coplayers [1]. There are various game types, including the prisoner's dilemma, hawk-dove game, battle of the sexes, and harmony games. Game theory originated in economics, but is today an interdisciplinary area of study, including political science, psychology, logic, and even biology [2]. For example, evolutionary game theory, which is derived from the combination of game theory and biology, has been under development for decades to focus on the interactions among macroscopic organisms [3]. Not only macroscopic organisms as a whole but also cells [1] and some macromolecules (RNAs [4], viruses [5], proteins) [6] within cells can be considered as players in game theory [6]. 
Life based on molecules is the highest and most complex expression of molecular interaction [7]. However, the molecular (or chemical) level has not been as well explored in game theory as interactions among macroscopic organisms or cells. As stated by Richard Feynman, for various interdisciplinary sciences, there is also plenty of room at the bottom [8]. Inspired by the natural logic of various information flows in life [9], simple biological systems and artificial molecular systems have been abstracted to develop biological $[10,11]$ or molecular computing devices, such as Boolean logic circuits [12,13], neural network computation [14,15], and molecular security systems [16-19], by utilizing engineered biological units (such as the living cell) as building blocks in life systems [10,11], biochemical molecules nucleic acids $[14,15,20]$, or organic molecules $[16,18]$ in complex chemical systems. However, using simple molecules to expand game theory for molecular decision-making remains a challenge.

The interaction between simple molecules offers a unique opportunity to expand game theory, such as the prisoner's dilemma, because molecular interactions (molecular competition, synergy, or decomposition) between two or more molecular players will create conflicts ("silent" or "betray") similar to those assumed in game theory [21]. Cognitive and rational capabilities are not prerequisites of players in game-theoretical models [6]. Thus, molecules with different states (regarded as strategies or decisions) can generate different outcomes of the whole system and individuals, which are described using a payoff matrix. From the perspective of combinatorial chemistry, nucleic acids with compositional and conformational diversity have various molecular interaction capabilities, such as specific recognition of aptamers [22], catalytic activity of DNAzymes [23], and interaction of DNA bases with metal ions [24]. For example, thymine- $\mathrm{Hg}^{2+}$-thymine $\left(\mathrm{T}-\mathrm{Hg}^{2+}-\mathrm{T}\right)$ and cytosine- $\mathrm{Ag}^{+}-$cytosine $\left(\mathrm{C}-\mathrm{Ag}^{+}-\mathrm{C}\right)$, have drawn considerable attention in sensing [24] and logic computing applications [25]. Because $\mathrm{Hg}^{2+}$ is capable of selectively coordinating $\mathrm{T}$ bases and forms a strong and stable $\mathrm{T}-\mathrm{Hg}^{2+}-\mathrm{T}$ mismatch [26], there is increasingly interest $[27,28]$ in the combination of $\mathrm{T}-\mathrm{Hg}^{2+}-\mathrm{T}$ [29] and nanomaterials (gold nanoparticles [30,31], graphene oxide [32], $\mathrm{MoS}_{2}$ [33], and quantum dots [34]) for $\mathrm{Hg}^{2+}$ sensing [35]. The combination not only provides a more accurate strategy for molecular sensing (such as reversible dual-signal sensing [36]), but also provides a universal and convenient model and platform to study molecular game theory.

Herein, we demonstrate a successful example of the application of game theory (prisoner's dilemma) to interactions among simple molecules, which relies on the hairpin structure of polythymine oligonucleotide 33-repeat thymines (T33) specifically induced by $\mathrm{Hg}^{2+}$ and fluorescence quenching and molecular adsorption capacities of cobalt oxyhydroxide $(\mathrm{CoOOH})$ nanosheets [37], resulting in fluorescence intensity and distribution change in T33. Two molecular players, $\mathrm{CoOOH}$ and $\mathrm{Hg}^{2}$, with different states $($ absence $=$ silence or presence $=$ betrayal), regarded as strategies, interact with the "bait" molecule T33 and create conflicts (sharing or self-interest) of fluorescence distribution of T33, quantifiable in a $2 \times 2$ payoff matrix. Because both $\mathrm{CoOOH}$ and $\mathrm{Hg}^{2+}$ competitively interact with $\mathrm{T} 33$ to form a $\mathrm{T}-\mathrm{Hg}^{2+}-\mathrm{T}-\mathrm{CoOOH}$ ternary complex, resulting in the largest signal change of the system, the molecular game-theoretical system was used to sensitively and selectively sense $\mathrm{Hg}^{2+}$. Inspired by the proof-of-concept of the feasibility of molecular game theory, a variety of molecular decision-making devices can be developed and applied, creating a new field of interdisciplinary science that would help to break through the traditional information processing paradigm and aid in the development of novel molecular intelligent decision systems for environmental monitoring and molecular diagnosis and therapy.

\section{Experiment Materials and Methods}

\subsection{Materials and Reagents}

The oligonucleotides used in this study were synthesized by Sangon Biotechnology Co., Ltd. (Shanghai, China), they have a carboxyfluorescein (FAM)-label on the $5^{\prime}$ end, and the sequences were composed of 33-repeat thymines (T33). Cobaltous chloride $\left(\mathrm{CoCl}_{2} \cdot 6 \mathrm{H}_{2} \mathrm{O}\right)$ was obtained from 
Sinopharm Chemical Reagent Co., Ltd. (Shanghai, China). Tris (hydroxymethyl) aminomethane (Tris), $\mathrm{NaOH}, \mathrm{NaClO}$, acridine orange, fluorescein, rhodamine $\mathrm{B}$, eosin $\mathrm{Y}$, calcein, and all of the metal salts used in this work were purchased from Aladdin Reagents Co., Ltd. (Shanghai, China). All reagents were of analytical grade. $\mathrm{Hg}^{2+}$ stock solution $(10 \mathrm{mM})$ was prepared by dissolving $\mathrm{Hg}\left(\mathrm{NO}_{3}\right)_{2}$ with $0.5 \% \mathrm{HNO}_{3}$. All reagents were used as received without further purification. All aqueous solutions were prepared with ultrapure water, which was provided by a Millipore Milli-Q water purification system (Bedford, MA, USA) and had an electric resistance $>18.2 \mathrm{M} \Omega \cdot \mathrm{cm}$.

\subsection{Instruments}

The transmission electron microscopy (TEM) images were collected on a Tecnai F20 transmission electron microscope (FEI, Hillsboro, OR, USA) operated at $120 \mathrm{kV}$. The scanning electron microscopy (SEM) images were collected on a SU8010 scanning electron microscope (Hitachi, Tokyo, Japan) operated at $2.0 \mathrm{kV}$. Zeta potential was carried out on a Malvern Zetasizer Nano ZS90 (UK). Atomic force microscopy (AFM) images were observed on a Bruker Multimode 8 AFM/SPM (Ettlingen, Germany) system in tapping mode and processed with freely available software: Gwyddion 2.30. The fluorescence spectra were measured using a SpectraMax M5 multi-mode microplate reader (Molecular Devices, San Jose, CA, USA) with the emission spectra ranging from $495 \mathrm{~nm}$ to $700 \mathrm{~nm}$ with an excitation of $485 \mathrm{~nm}$ at room temperature. The ultraviolet-visible (UV-Vis) absorption spectra were acquired from a DR6000 UV-Vis spectrophotometer (Hach, Loveland, CO, USA). Circular dichroism (CD) spectra were performed on a MOS-500 circular dichroism spectrometer (Bio-Logic, Seyssinet-Pariset, France) with a $0.1 \mathrm{~cm}$ quartz cell at $200-350 \mathrm{~nm}$ using standard procedures.

\subsection{Synthesis of Cobalt Oxyhydroxide ( $\mathrm{CoOOH})$ Nanosheets}

The $\mathrm{CoOOH}$ nanosheets were synthesized per a previously reported method [37]. First, $125 \mu \mathrm{L}$ of sodium hydroxide $(\mathrm{NaOH}, 1 \mathrm{M})$ was added to $500 \mu \mathrm{L}$ of $\mathrm{CoCl}_{2} \cdot 6 \mathrm{H}_{2} \mathrm{O}$ solution $(10 \mathrm{mM})$, and then the mixture was sonicated for $1 \mathrm{~min}$. Then, $25 \mu \mathrm{L}$ of sodium hypochlorite solution $(\mathrm{NaClO}, 0.9 \mathrm{M})$ was added to the mixture and sonicated for $10 \mathrm{~min}$. Subsequently, the mixture was centrifuged at 14,000 rpm for $15 \mathrm{~min}$ and washed three times with deionized water. Finally, the product was re-dispersed in $1 \mathrm{~mL}$ of water to a final concentration of $0.25 \mathrm{mg} / \mathrm{mL}$ and stored at room temperature for further use.

\subsection{Construction and Demonstration of Molecular Game-Theoretical System and Application in Sensing Metal Ions}

Firstly, the T33 solution was diluted $100 \mu \mathrm{M}$ to $100 \mathrm{nM}$ using the Tris- $\mathrm{HCl}$ buffer solution ( $5 \mathrm{mM}$, $\mathrm{pH}$ 7.4). Then, $7.5 \mu \mathrm{L}$ of $\mathrm{CoOOH}(0.25 \mathrm{mg} / \mathrm{mL})$, after ultrasonication for $30 \mathrm{~min}$, was added to $400 \mu \mathrm{L}$ of T33 solution (100 nM), resulting in a T33-CoOOH complex (100 nM T33, $4.69 \mu \mathrm{g} / \mathrm{mL}$ CoOOH). The initial fluorescence spectrum of the $\mathrm{T} 33-\mathrm{CoOOH}$ mixture after $4 \mathrm{~min}$ of reaction was measured. Afterward, upon addition of different concentration of metal ions, the fluorescence spectra of T33 and the resulting T33-CoOOH complex were measured after $3 \mathrm{~min}$ of reaction. Finally, the fluorescence intensity was normalized and quenching ratio (F0 - F)/F0 was calculated.

\subsection{Real Sample Analysis}

A pond water sample from the Yuewang Pavilion of Hunan Normal University (Changsha, China) was filtered through a $0.2-\mu \mathrm{m}$ membrane and then boiled for $5 \mathrm{~min}$. Then, the pond water $(5 \mu \mathrm{L})$ and standard solutions $(5 \mu \mathrm{L})$ containing different amounts of $\mathrm{Hg}^{2+}$ were added into the T33-CoOOH complex $(400 \mu \mathrm{L}, 100 \mathrm{nM} \mathrm{T33}, 4.69 \mu \mathrm{g} / \mathrm{mL} \mathrm{CoOOH})$. After incubation for $3 \mathrm{~min}$ at room temperature, the fluorescence of the resulting mixtures was measured and calculated. 


\section{Results and Discussion}

\subsection{Construction and Characterization of Molecular Game-Theoretical System Based on Molecular Interactions}

We first constructed an artificial molecular system based on molecular interactions among polythymine oligonucleotide $\mathrm{T} 33$, metal ions $\left(\mathrm{Hg}^{2+}\right)$, and $\mathrm{CoOOH}$ nanosheets (Figure 1). FAM-labeled T33 random coils in aqueous solution had strong fluorescence (normalized F = 1.0 a.u.) at $520 \mathrm{~nm}$. Due to its unique fluorescence quenching and molecular adsorption capacities (Figure S1) [37], when positively charged hexagonal CoOOH nanosheets (TEM and SEM images in Figure S2A) were added into the solution, the negatively charged T33 adsorbed onto the surface of CoOOH nanosheets, resulting in fluorescence quenching (normalized $\mathrm{F}=0.67$ a.u., Figure $1 \mathrm{a}$ ). This result may be attributed to the electrostatic adsorption (Figure S3) of T33 on CoOOH nanosheets and the effective fluorescence resonance energy transfer (FRET) between FAM and CoOOH nanosheets (Figure S2B) [38,39]. Only in the presence of $\mathrm{Hg}^{2+}$ did $\mathrm{T} 33$ change its conformation from a random coil to a $\mathrm{T}-\mathrm{Hg}^{2+}-\mathrm{T}$ hairpin structure, resulting in slight fluorescence quenching (normalized $F=0.96$ a.u., Figure $1 b$ ). In the simultaneous presence of $\mathrm{CoOOH}$ and $\mathrm{Hg}^{2+}, \mathrm{Hg}^{2+}$ may combine with $\mathrm{T} 33$ on the CoOOH nanosheets to form a $\mathrm{T}-\mathrm{Hg}^{2+}-\mathrm{T}$ hairpin structure, which increases the tightness of the bond of the three components, resulting in stronger quenching (normalized $F=0.3$ a.u., Figure $1 c$ ).
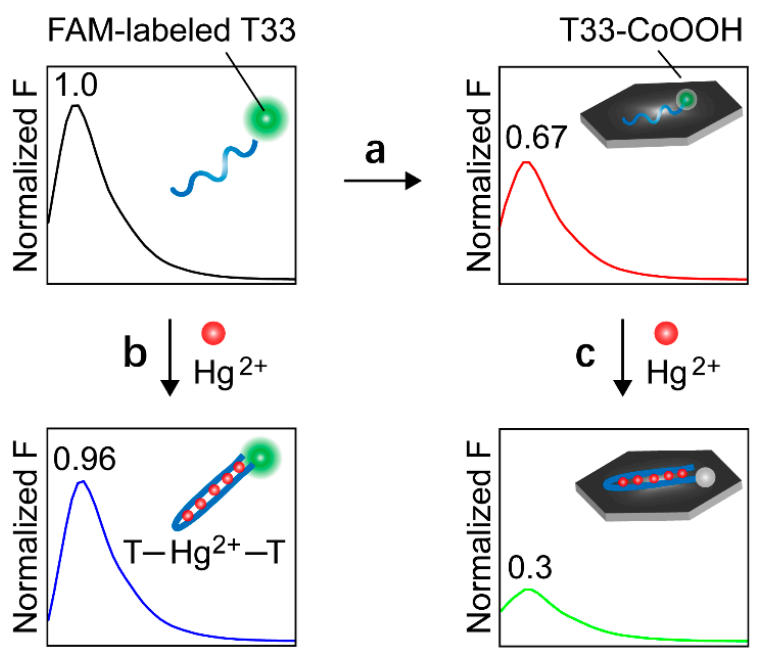

Figure 1. Schematic illustration and fluorescence emission spectra change of an artificial molecular system based on molecular interactions among polythymine oligonucleotide $\mathrm{T} 33$, metal ions $\left(\mathrm{Hg}^{2+}\right)$, $\mathrm{CoOOH}$ nanosheets. $(\mathbf{a}-\mathbf{c})$ the formation of $\mathrm{T} 33-\mathrm{CoOOH}(\mathbf{a}) ; \mathrm{T}-\mathrm{Hg}^{2+}-\mathrm{T}$ pairs $(\mathbf{b})$; $\mathrm{T} 33-\mathrm{CoOOH}-\mathrm{Hg}^{2+}$ (c). T33: $100 \mathrm{nM}, \mathrm{CoOOH}$ nanosheets: $4.69 \mu \mathrm{g} / \mathrm{mL}, \mathrm{Hg}^{2+}: 10 \mu \mathrm{M}$. The excitation and emission wavelength are 485 and $520 \mathrm{~nm}$. The fluorescence intensity is normalized. Buffer: $5 \mathrm{mM}$ Tris-HCl buffer solution (pH 7.4); FAM: carboxyfluorescein; $\mathrm{CoOOH}$ : cobalt oxyhydroxide.

Atomic force microscopy (AFM), UV-Vis absorption spectroscopy, and CD) spectroscopy were used to characterize the above-mentioned molecular interaction process. The AFM results showed that the thickness of the $\mathrm{CoOOH}$ nanosheets was $12-16 \mathrm{~nm}$ (Figure $2 \mathrm{~A}, n=15$ ). The thickness of the T33-CoOOH composites increased to 15-19 nm (Figure 2B, $n=15$ ), indicating that T33 was adsorbed on the $\mathrm{CoOOH}$ nanosheets. The thickness of the T33-CoOOH- $\mathrm{Hg}^{2+}$ mixture increased to $21-23 \mathrm{~nm}$ (Figure $2 \mathrm{C}, n=15$ ). Figure 3A shows the absorption spectra of T33 and T33-CoOOH in the presence of various concentrations of $\mathrm{Hg}^{2+}$. The optical density decreased as $\mathrm{Hg}^{2+}$ concentration increased and their absorption spectra displayed a slight redshift $(264 \rightarrow 270 \mathrm{~nm}$, Figure 3A). In Figure 3B, CD spectra of T33 and T33-CoOOH in the presence of various concentrations of $\mathrm{Hg}^{2+}$ are shown. After the addition of $\mathrm{Hg}^{2+}$, the positive band at $278 \mathrm{~nm}$ reduced. The experimental results clearly indicate the formation of $\mathrm{T}-\mathrm{Hg}^{2+}-\mathrm{T}$ pairs [40]. By further comparison with the fluorescence changes of free fluorescein, T3, and T33-CoOOH complex, at the different concentrations of $\mathrm{Hg}^{2+}$, the fluorescence 
of free fluorescein and T33 slightly decreased with increasing concentration of $\mathrm{Hg}^{2+}$ (Figure S4), indicating that the $\mathrm{CoOOH}$ nanosheets play an important role in enhancing the sensitivity of $\mathrm{Hg}^{2+}$ detection. We further investigated fluorescence responses of the T33-CoOOH complex to T33's fully complementary DNA A33. As a result, the formation of a T33-A33 duplex DNA also lead to similar quenching (normalized F from 0.67 to 0.51 a.u., Figure 3C). Thymine residues in T33 preferentially bind to $\mathrm{Hg}^{2+}$ through covalent $\mathrm{N}-\mathrm{Hg}$ bonds [40]. $\mathrm{Co}^{3+}$ ions, which easily coordinate with nitrogen and oxygen atoms [41,42], likely bind to the remaining oxygen atoms of thymine residues. Thus, $\mathrm{Hg}^{2+}$ may combine with $\mathrm{T} 33$ on the $\mathrm{CoOOH}$ nanosheets to form a $\mathrm{T}-\mathrm{Hg}^{2+}-\mathrm{T}$ hairpin structure, which causes the three components to bind more tightly [43], probably due to the coordination of $\mathrm{Co}^{3+}$ of the $\mathrm{CoOOH}$ nanosheets to the oxygen atoms of $\mathrm{T}-\mathrm{Hg}^{2+}-\mathrm{T}$ complexes.
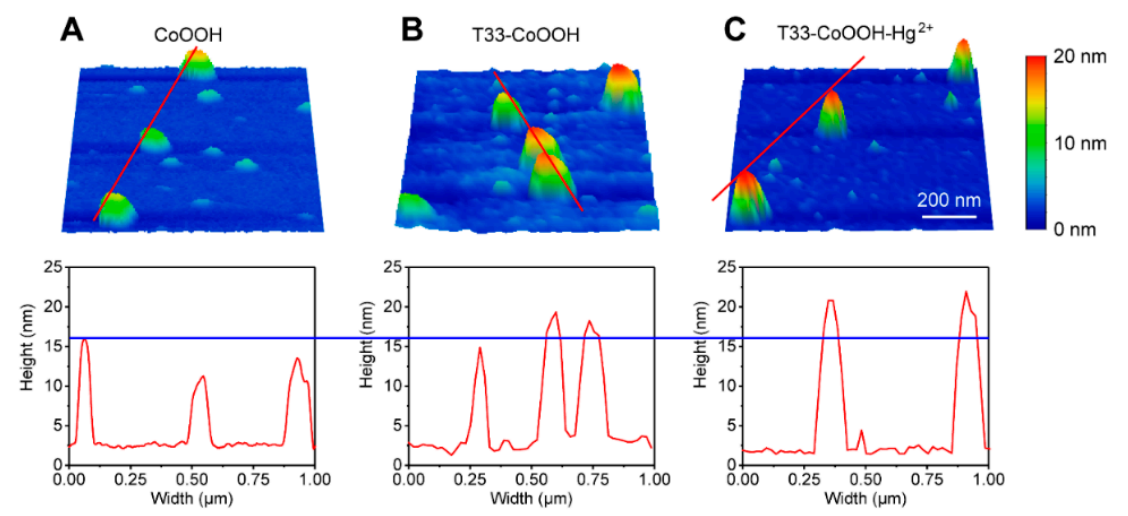

Figure 2. Representative atomic force microscopy (AFM) images and height analysis of (A) $\mathrm{CoOOH}$; (B) T33-CoOOH; and (C) T33-CoOOH- $\mathrm{Hg}^{2+}$.
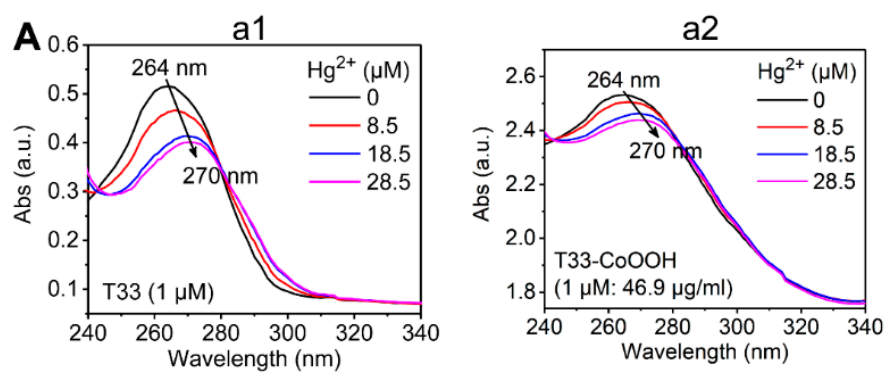

B b1
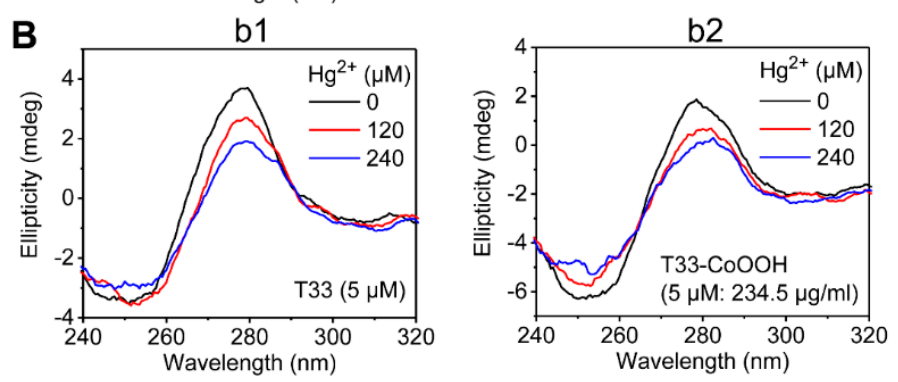

C
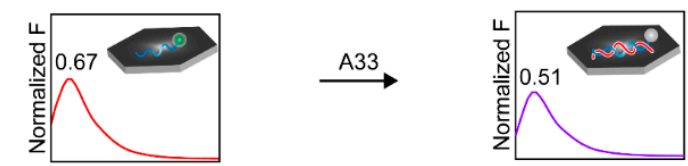

Figure 3. (A) Absorption response of T33 (a1, $1 \mu \mathrm{M})$ and T33-CoOOH (a2, $1 \mu \mathrm{M}: 46.9 \mu \mathrm{g} / \mathrm{mL})$ on addition of $\mathrm{Hg}^{2+}$ ions; (B) CD spectra of T33 (b1, $\left.5 \mu \mathrm{M}\right)$ and T33-CoOOH (b2, $\left.5 \mu \mathrm{M}: 234.5 \mu \mathrm{g} / \mathrm{mL}\right)$ on addition of $\mathrm{Hg}^{2+}$ ions. Buffer: $5 \mathrm{mM}$ Tris- $\mathrm{HCl}, \mathrm{pH} 7.4$; (C) Fluorescence responses of the T33-CoOOH complex to T33's fully complementary DNA A33. T33: $100 \mathrm{nM}, \mathrm{CoOOH}$ nanosheets: $4.69 \mu \mathrm{g} / \mathrm{mL}, \mathrm{A} 33$ : $300 \mathrm{nM}$. 


\subsection{Demonstration of Molecular Game-Theoretical System}

Game theory is an effective and powerful tool for analyzing strategic interactions between two or more agents or players. The prisoner's dilemma, a game theory classic, is a paradox in decision analysis in which acting for individual interests is pitted against acting for collective advantage. Generally, each player in the game chooses either "silence" or "betrayal" [21]. If both players are silent, they both receive the reward R. If both players betray, they both receive the punishment payoff $P$. If one betrays and the other keeps silent, the defector receives the temptation payoff $\mathrm{T}$, while the silencer receives the "sucker's" payoff S. The rank order of payoffs (Figure $4 \mathrm{~A}$ ) is usually $\mathrm{T}>\mathrm{R}>\mathrm{P}>\mathrm{S}$. Because pursuing individual reward logically leads both players to betray, they would receive a better reward if both remain silent as $2 R>T+S$.

With the development of game theory in biology (especially at the cellular level), there are some predictions that game theory could be useful in the interpretation of molecular systems $[1,6]$. To extend game-theoretic treatment to an abiotic situation, our above-mentioned constructed artificial molecular system is a successful example of the application of game theory (prisoner's dilemma) to interactions among simple molecules, which relies on the hairpin structure of T33, specifically induced by $\mathrm{Hg}^{2+}$ and fluorescence quenching, and the molecular adsorption capacities of $\mathrm{CoOOH}$ nanosheets [37], resulting in fluorescence intensity and a distribution change in T33 (Figure 4B). From a game theory perspective, the molecular interaction of the "bait" molecule T33 with $\mathrm{CoOOH}$ and $\mathrm{Hg}^{2+}$ can be considered a "game" in which $\mathrm{CoOOH}$ and $\mathrm{Hg}^{2+}$ have two possible states: absence (silence) or presence (betrayal) regarded as two possible strategies, resulting in conflicts (sharing or self-interest) of the fluorescence distribution of T33, which conforms to the prisoner's dilemma. If both were absent (silent) and the bait molecule T33 did not interact with them, exhibiting its full fluorescence in which that payoff of the whole system was represented as 1 , and then each molecular player was equivalent to share the average payoff $R=$ 0.5. If one was absent (silent) and the other was present (betrayal), the existing one selfishly interacted with T33 to form the complex, resulting in fluorescence quenching. That is, in the presence (betrayal) of $\mathrm{CoOOH}$ and absence (silence) of $\mathrm{Hg}^{2+}, \mathrm{CoOOH}$ selfishly owned the whole system's payoff $\mathrm{T}+\mathrm{S}=$ 0.67 (note that $\mathrm{T}=0.67, \mathrm{~S}=0$ ). Payoff $\mathrm{S}$ of $\mathrm{Hg}^{2+}$ was zero. Similarly, in the presence betrayal") ${\mathrm{of} \mathrm{Hg}^{2+}}^{2+}$ and absence (silence) of $\mathrm{CoOOH}, \mathrm{Hg}^{2+}$ selfishly owned the whole system's payoff $\mathrm{T}+\mathrm{S}=0.96$ (note that $\mathrm{T}=0.96, \mathrm{~S}=0$ ), payoff $\mathrm{S}$ of $\mathrm{CoOOH}$ was zero. If both were present (betrayal), both competitively interacted with $\mathrm{T} 33$ to form $\mathrm{T}-\mathrm{Hg}^{2+}-\mathrm{T}-\mathrm{CoOOH}$ ternary complex, resulting in stronger quenching of T33. Each molecular player received punishment (payoff $\mathrm{P}=0.15$ ), the payoff of the whole system was lowest $(2 \mathrm{P}=0.3)$. In this molecular game-theoretical system, the payoff of each molecular player is determined not only by its own state, but also by the state adopted by the molecular coplayers.

A

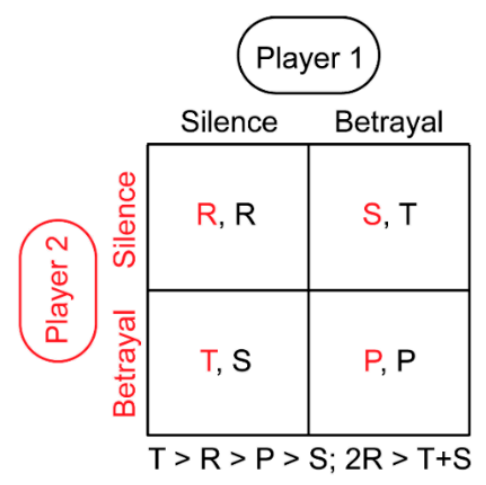

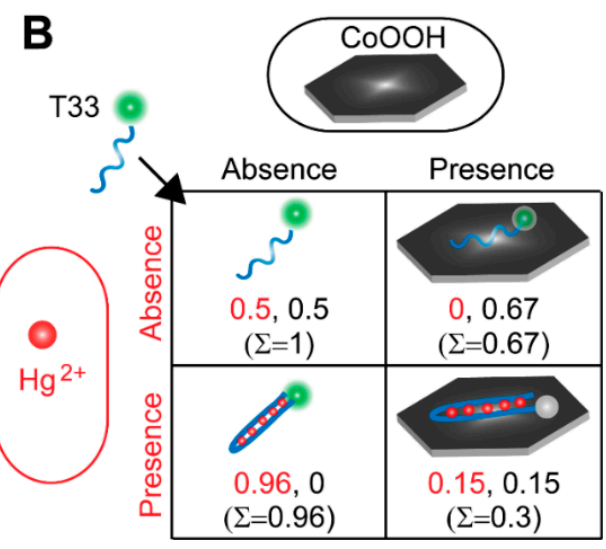

Figure 4. (A) Generalized payoff matrix for prisoner's dilemma where the two players are represented by red and black, and each player chooses to either silence or betrayal; (B) Realized payoff matrix for the molecular interaction of the bait molecule $\mathrm{T} 33$ with two molecular players, $\mathrm{CoOOH}$ and $\mathrm{Hg}^{2+}$, with different states (absence $=$ silence and presence $=$ betrayal) regarded as strategies, resulting in conflicts (sharing or self-interest) of fluorescence distribution change of T33, which conforms to the prisoner's dilemma. 


\subsection{Molecular Game-Theoretical System for Sensing $\mathrm{Hg}^{2+}$}

According to the demonstration process of above-mentioned molecular game-theoretical system, both $\mathrm{CoOOH}$ and $\mathrm{Hg}^{2+}$ competitively interacted with $\mathrm{T} 33$ to form the $\mathrm{T}-\mathrm{Hg}^{2+}-\mathrm{T}-\mathrm{CoOOH}$ ternary complex, resulting in the largest signal change (payoff from $2 \mathrm{R}=1.0$ to $2 \mathrm{P}=0.3$ ) of the whole system, suggesting that the T33-CoOOH complex sensitively senses $\mathrm{Hg}^{2+}$. Under optimum conditions $(100 \mathrm{nM}$ T33, $4.69 \mu \mathrm{g} / \mathrm{mL} \mathrm{CoOOH}, 5 \mathrm{mM}$ Tris-HCl, pH 7.4, Figures S5 and S6), the T33-CoOOH complex was used for detection of $\mathrm{Hg}^{2+}$. As shown in Figure 5A, the fluorescence intensity gradually decreased with increasing concentration of $\mathrm{Hg}^{2+}$ from 0 to $2000 \mathrm{nM}$. Similarly, the fluorescence quenching ratio $(\mathrm{F} 0-\mathrm{F}) / \mathrm{F} 0$ gradually increased with increasing concentration of $\mathrm{Hg}^{2+}$ from 0 to $2000 \mathrm{nM}$ (Figure 5B). Figure 5C shows the good linear relationship between the value of (F0 - F) /F0 and the $\mathrm{Hg}^{2+}$ concentration in the range of 20 to $600 \mathrm{nM}$. The calibration equation was $\mathrm{y}=0.00036 \mathrm{x}+0.04076$ with a correlation coefficient $\left(R^{2}\right)$ of 0.995 . The limit of detection was $7.94 \mathrm{nM}$ according to the $3 \sigma$ rule, which is below the maximum level $(10 \mathrm{nM})$ of $\mathrm{Hg}^{2+}$ permitted by the U.S. Environmental Protection Agency for drinking water. Compared with other previously reported $\mathrm{Hg}^{2+}$ assays, our proposed approach has a much lower detection limit (Table S1). The result indicates that the molecular game-theoretical system based on $\mathrm{T} 33$ and $\mathrm{CoOOH}$ nanosheets can sensitively detect $\mathrm{Hg}^{2+}$.
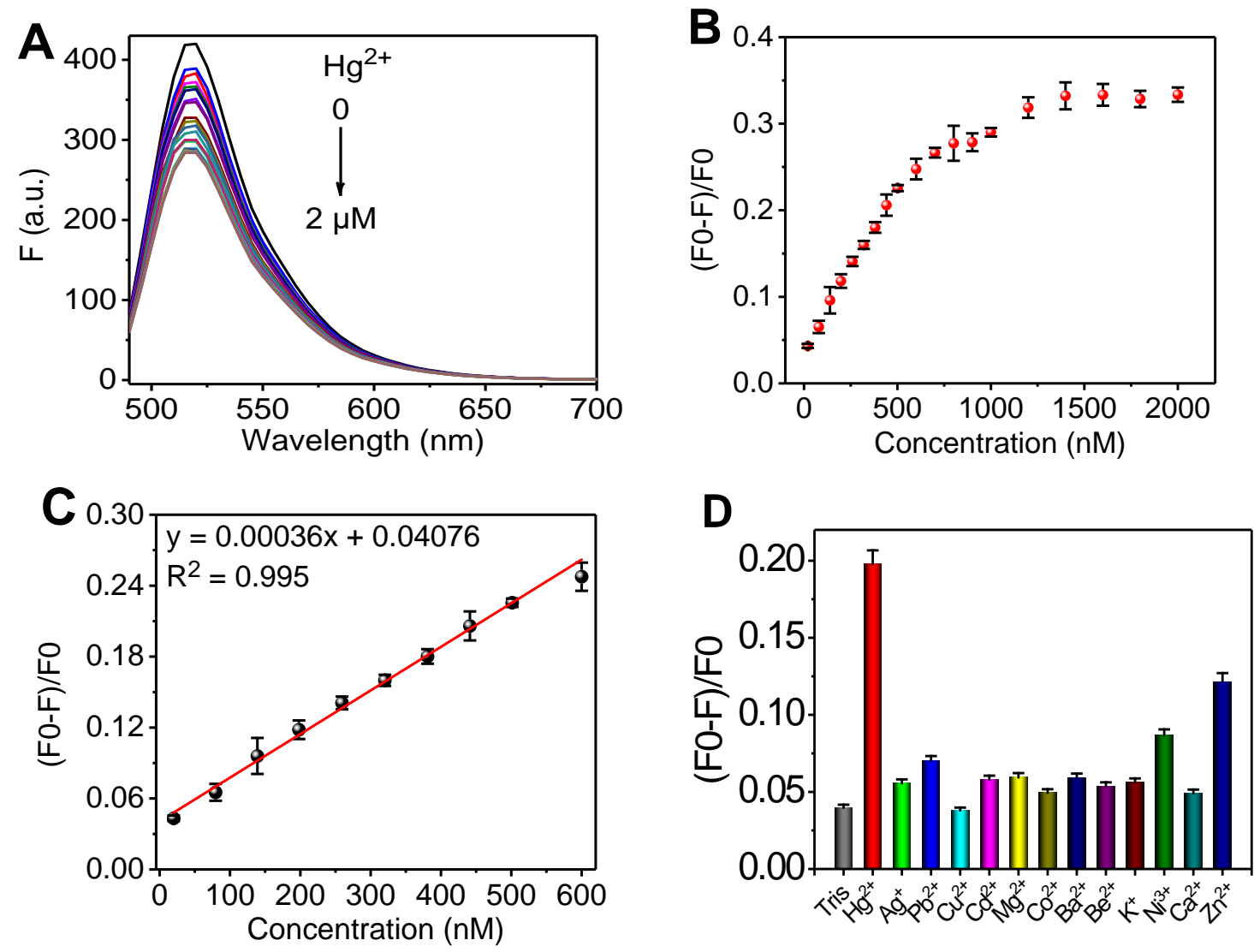

Figure 5. (A) Fluorescence emission spectra of T33-CoOOH complex (100 nM:4.69 $\mu \mathrm{g} / \mathrm{mL})$ upon addition of various concentrations of $\mathrm{Hg}^{2+}$ (from top to bottom: 0, 20, 80, 139, 198, 259, 320, 381, $441,500,600,700,800,900,1000,1200,1400,1600,1800$, and $2000 \mathrm{nM}$ ); (B) The dependence of the fluorescence intensity changes (F0 - F)/F0 at $520 \mathrm{~nm}$ on the concentration of $\mathrm{Hg}^{2+}$; (C) The linear relationship between $(\mathrm{F} 0-\mathrm{F}) / \mathrm{F} 0$ and the $\mathrm{Hg}^{2+}$ concentrations in the range from 20 to $600 \mathrm{nM}$; (D) The selectivity of the T33-CoOOH complex $(100 \mathrm{nM}: 4.69 \mu \mathrm{g} / \mathrm{mL})$ for $\mathrm{Hg}^{2+}$ assay $\left(\mathrm{Hg}^{2+}: 600 \mathrm{nM}\right.$, other metal ions: $1.2 \mu \mathrm{M})$. Buffer: $5 \mathrm{mM}$ Tris- $\mathrm{HCl}, \mathrm{pH}$ 7.4. 
To further evaluate the specificity of the T33- $\mathrm{CoOOH}$ complex under optimum conditions, we first investigated the responses of our method to $\mathrm{Hg}^{2+}(600 \mathrm{nM})$ against other metal ions $\left(\mathrm{Ag}^{+}\right.$, $\mathrm{Pb}^{2+}, \mathrm{Cu}^{2+}, \mathrm{Cd}^{2+}, \mathrm{Mg}^{2+}, \mathrm{Co}^{2+}, \mathrm{Ba}^{2+}, \mathrm{Be}^{2+}, \mathrm{K}^{+}, \mathrm{Ni}^{3+}$, and $\mathrm{Ca}^{2+}$; each $\left.1.2 \mu \mathrm{M}\right)$. As shown in the Figure 5D, the T33-CoOOH complex was highly selective for sensing $\mathrm{Hg}^{2+}$, although the concentration of other interfering metal ions was much higher (two-fold) than that of $\mathrm{Hg}^{2+} . \mathrm{Zn}^{2+}$ exhibited a certain degree of interference. $\mathrm{Zn}^{2+}$ may incorporate into $\mathrm{CoOOH}$ for formation of $\mathrm{Zn}$-doped $\mathrm{CoOOH}[44,45]$ and $\mathrm{Zn}$-doped $\mathrm{CoOOH}$ may bind to thymines, probably by interacting with the $\mathrm{Zn}^{2+}$ metal center with the deprotonated N3 imide of thymine and stacking the aromatic pendent group on the thymine nucleobase [46,47].

A competition experiment in the presence of potentially competitive metal ions was also performed to further confirm the selectivity of this sensing system toward $\mathrm{Hg}^{2+}$. As shown in Figure $\mathrm{S7A}, \mathrm{Hg}^{2+}$ can efficiently quench the fluorescence of this sensing system even if the other metal ions slightly affected the fluorescence intensity. As shown in Figure S7B, common anions did not remarkably affect the fluorescence change. In addition, the fluorescence quenching ratio (F0 - F)/F0 gradually increased with increasing concentration of A33 from 20 to $270 \mathrm{nM}$, and there was a good linear relationship between the quenching ratio (F0 - F) /F0 and the $\mathrm{A} 33$ concentration in the range of 20 to $270 \mathrm{nM}\left(\mathrm{y}=0.00091 \mathrm{x}+0.00447, R^{2}=0.992\right.$, Figure S8).

We applied the T33-CoOOH complex to determinate the concentration of $\mathrm{Hg}^{2+}$ in pond water, to evaluate its performance in a real water sample. In order to avoid the adverse effects of sediments and nucleases in the real water sample on the sensing system, we first filtered and boiled the real water sample. As shown in Table 1, the spike recovery for $\mathrm{Hg}^{2+}$ in the concentration ranged from 104.93 to $108.29 \%$, and the relative standard deviation (RSD) ranged from 0.59 to $1.15 \%$, which indicated the developed method has great potential for detection $\mathrm{Hg}^{2+}$ in real water samples.

Table 1. Determination of $\mathrm{Hg}^{2+}$ in real water samples $(n=3)$.

\begin{tabular}{ccccc}
\hline Sample & Added (nM) & Found (nM) & Recovery (\%) & RSD (\%) \\
\hline \multirow{2}{*}{ Pond water } & 84.00 & 90.96 & 108.29 & 0.59 \\
& 155.00 & 162.64 & 104.93 & 1.15 \\
\hline
\end{tabular}

\section{Conclusions}

In summary, we demonstrated a proof-of-concept molecular game-theoretical system (molecular prisoner's dilemma) that relies on the formation of the $\mathrm{T}-\mathrm{Hg}^{2+}-\mathrm{T}$ hairpin structure specifically induced by $\mathrm{Hg}^{2+}$ and fluorescence quenching and molecular adsorption capacities of $\mathrm{CoOOH}$ nanosheets, resulting in fluorescence intensity and distribution change in polythymine oligonucleotide T33. The bait molecule T33 interacted with two molecular players, $\mathrm{CoOOH}$ and $\mathrm{Hg}^{2+}$, with different states (absence $=$ silence and presence = betrayal) regarded as strategies, and created conflicts (sharing or self-interest) of fluorescence distribution of T33, quantifiable in a $2 \times 2$ payoff matrix. The molecular game-theoretical system based on $\mathrm{T} 33$ and $\mathrm{CoOOH}$ was used for sensing $\mathrm{Hg}^{2+}$ in the range of 20 to $600 \mathrm{nM}$ with a detection limit of $7.94 \mathrm{nM}(3 \sigma)$ and for determination of $\mathrm{Hg}^{2+}$ in pond water. Although the demonstrated molecular game system is relatively simple, it has high versatility and broad applicability and can be extended to various other molecular systems, such as RNA/DNA/peptide-based systems, nano-based systems, host-guest supramolecular systems, and solid-phase molecular self-assembly systems. Inspired by the proof-of-concept for the feasibility of molecular game theory, a variety of molecular decision-making platforms will be developed, which will help promote molecular information processing and generating novel molecular intelligent decision systems for environmental monitoring and molecular diagnosis and therapy. 
Supplementary Materials: The following are available online at http:/ /www.mdpi.com/2076-3417/8/12/2530/ s1, Figure S1: Comparison of fluorescence quenching ability of $\mathrm{CoOOH}$ to different fluorescence dyes. Figure S2: Characterization of $\mathrm{CoOOH}$ nanosheets. Figure S3: Comparison of $\zeta$-potential for $\mathrm{CoOOH}, \mathrm{T} 33-\mathrm{CoOOH}$, and $\mathrm{T} 33-\mathrm{CoOOH}-\mathrm{Hg}^{2+}$ mixtures. Figure S4: Comparison of fluorescence changes in free fluorescein, T33, and $\mathrm{T} 33-\mathrm{CoOOH}$ complexes at different concentrations of $\mathrm{Hg}^{2+}$. Figure S5: Optimization of the concentration of $\mathrm{CoOOH}$ nanosheets. Figure S6: Optimization of reaction time. Figure S7: Competition experiment and the interference of anions. Figure S8: T33-CoOOH complexes for detection of A33 DNA. Table S1: Comparison of the detection slimit and linear ranges of other reported $\mathrm{Hg}^{2+}$ assays.

Author Contributions: W.T.H. designed the methods, N.F.N. and X.X.Z. performed the experiments, and optimized the parameters; C.S.F., Q.Y.Z., J.Y.L., F.R.Z., and Q.F.Y. optimized the process and analyzed the data, W.T.H. and N.F.N wrote the paper; X.Z.D. and L.Q.X. performed review and editing. The first two authors contributed equally to this paper.

Funding: This work was supported by the National Natural Science Foundation of China (No. 21505042), Scientific and Technological Plan Project of Changsha of China (No. KQ1707010 and KQ1802046), Hunan Provincial Natural Science Foundation of China (No. 2016JJ3084), the Research Foundation of Education Bureau of Hunan Province (No. 15K084), the Cooperative Innovation Center of Engineering and New Products for Developmental Biology of Hunan Province (No. 20134486), and College Student Innovative Experiment Project of Hunan Province (No. 2017106).

Conflicts of Interest: The authors declare no conflict of interest.

\section{References}

1. Hummert, S.; Bohl, K.; Basanta, D.; Deutsch, A.; Werner, S.; Theissen, G.; Schroeter, A.; Schuster, S. Evolutionary game theory: Cells as players. Mol. Biosyst. 2014, 10, 3044-3065. [CrossRef]

2. Sanfey, A.G. Social Decision-Making: Insights from Game Theory and Neuroscience. Science 2007, 318, 598-602. [CrossRef]

3. Nowak, M.A.; Sasaki, A.; Taylor, C.; Fudenberg, D. Emergence of cooperation and evolutionary stability in finite populations. Nature 2004, 428, 646-650. [CrossRef]

4. Yeates, J.A.M.; Hilbe, C.; Zwick, M.; Nowak, M.A.; Lehman, N. Dynamics of prebiotic RNA reproduction illuminated by chemical game theory. Proc. Natl. Acad. Sci. USA 2016, 113, 5030-5035. [CrossRef]

5. Turner, P.E.; Chao, L. Prisoner's dilemma in an RNA virus. Nature 1999, 398, 441-443. [CrossRef]

6. Bohl, K.; Hummert, S.; Werner, S.; Basanta, D.; Deutsch, A.; Schuster, S.; Theissen, G.; Schroeter, A. Evolutionary game theory: Molecules as players. Mol. Biosyst. 2014, 10, 3066-3074. [CrossRef]

7. Vaidya, N.; Manapat, M.L.; Chen, I.A.; Xulvi-Brunet, R.; Hayden, E.J.; Lehman, N. Spontaneous network formation among cooperative RNA replicators. Nature 2012, 491, 72-77. [CrossRef]

8. Feynman, R.P. There's plenty of room at the bottom: An invitation to enter a new field of physics. In Handbook of Nanoscience, Engineering, and Technology, 3rd ed.; CRC Press: Boca Raton, FL, USA, 2012; pp. 26-35.

9. Nurse, P. Life, logic and information. Nature 2008, 454, 424-426. [CrossRef]

10. Ausländer, D.; Ausländer, S.; Pierrat, X.; Hellmann, L.; Rachid, L.; Fussenegger, M. Programmable full-adder computations in communicating three-dimensional cell cultures. Nat. Methods 2017, 15, 57-60. [CrossRef]

11. Green, A.A.; Kim, J.; Ma, D.; Silver, P.A.; Collins, J.J.; Yin, P. Complex cellular logic computation using ribocomputing devices. Nature 2017, 548, 117-121. [CrossRef]

12. Erbas-Cakmak, S.; Kolemen, S.; Sedgwick, A.C.; Gunnlaugsson, T.; James, T.D.; Yoon, J.; Akkaya, E.U. Molecular logic gates: The past, present and future. Chem. Soc. Rev. 2018, 47, 2228-2248. [CrossRef]

13. Szaciłowski, K. Digital Information Processing in Molecular Systems. Chem. Rev. 2008, 108, 3481-3548. [CrossRef]

14. Cherry, K.M.; Qian, L. Scaling up molecular pattern recognition with DNA-based winner-take-all neural networks. Nature 2018, 559, 370-376. [CrossRef]

15. Qian, L.; Winfree, E.; Bruck, J. Neural network computation with DNA strand displacement cascades. Nature 2011, 475, 368-372. [CrossRef]

16. Boukis, A.C.; Reiter, K.; Froelich, M.; Hofheinz, D.; Meier, M.A.R. Multicomponent reactions provide key molecules for secret communication. Nat. Commun. 2018, 9, 1439. [CrossRef]

17. Lustgarten, O.; Motiei, L.; Margulies, D. User Authorization at the Molecular Scale. ChemPhysChem 2017, 18, 1678-1687. [CrossRef] 
18. Huang, W.T.; Chen, L.X.; Lei, J.L.; Luo, H.Q.; Li, N.B. Molecular neuron: From sensing to logic computation, information encoding, and encryption. Sens. Actuator B-Chem. 2017, 239, 704-710. [CrossRef]

19. Andréasson, J.; Pischel, U. Molecules for security measures: From keypad locks to advanced communication protocols. Chem. Soc. Rev. 2018, 47, 2266-2279. [CrossRef]

20. Chatterjee, G.; Dalchau, N.; Muscat, R.A.; Phillips, A.; Seelig, G. A spatially localized architecture for fast and modular DNA computing. Nat. Nanotechnol. 2017, 12, 920-927. [CrossRef]

21. Schuster, S.; Kreft, J.U.; Schroeter, A.; Pfeiffer, T. Use of Game-Theoretical Methods in Biochemistry and Biophysics. J. Biol. Phys. 2008, 34, 1-17. [CrossRef]

22. Liu, J.; Cao, Z.; Lu, Y. Functional Nucleic Acid Sensors. Chem. Rev. 2009, 109, 1948-1998. [CrossRef] [PubMed]

23. Zhang, X.B.; Kong, R.M.; Lu, Y. Metal Ion Sensors Based on DNAzymes and Related DNA Molecules. Ann. Rev. Anal. Chem. 2011, 4, 105-128. [CrossRef] [PubMed]

24. Li, L.; Wen, Y.; Xu, L.; Xu, Q.; Song, S.; Zuo, X.; Yan, J.; Zhang, W.; Liu, G. Development of mercury (II) ion biosensors based on mercury-specific oligonucleotide probes. Biosens. Bioelectron. 2016, 75, 433-445. [CrossRef] [PubMed]

25. Park, K.S.; Jung, C.; Park, H.G. "Illusionary" Polymerase Activity Triggered by Metal Ions: Use for Molecular Logic-Gate Operations. Angew. Chem. Int. Ed. 2010, 49, 9757-9760. [CrossRef] [PubMed]

26. Liu, J.; Lu, Y. Rational Design of “Turn-On” Allosteric DNAzyme Catalytic Beacons for Aqueous Mercury Ions with Ultrahigh Sensitivity and Selectivity. Angew. Chem. Int. Ed. 2007, 46, 7587-7590. [CrossRef] [PubMed]

27. Li, J.; Lu, L.; Kang, T.; Cheng, S. Intense charge transfer surface based on graphene and thymine-Hg(II)-thymine base pairs for detection of $\mathrm{Hg}^{2+}$. Biosens. Bioelectron. 2016, 77, 740-745. [CrossRef] [PubMed]

28. Zhu, Z.; Su, Y.; Li, J.; Li, D.; Zhang, J.; Song, S.; Zhao, Y.; Li, G.; Fan, C. Highly Sensitive Electrochemical Sensor for Mercury(II) Ions by Using a Mercury-Specific Oligonucleotide Probe and Gold Nanoparticle-Based Amplification. Anal. Chem. 2009, 81, 7660-7666. [CrossRef]

29. Chiang, C.K.; Huang, C.C.; Liu, C.W.; Chang, H.T. Oligonucleotide-based fluorescence probe for sensitive and selective detection of mercury (II) in aqueous solution. Anal. Chem. 2008, 80, 3716-3721. [CrossRef]

30. Chen, G.H.; Chen, W.Y.; Yen, Y.C.; Wang, C.W.; Chang, H.T.; Chen, C.F. Detection of mercury (II) ions using colorimetric gold nanoparticles on paper-based analytical devices. Anal. Chem. 2014, 86, 6843-6849. [CrossRef]

31. Xie, W.Y.; Huang, W.T.; Zhang, J.R.; Luo, H.Q.; Li, N.B. A triple-channel optical signal probe for $\mathrm{Hg}^{2+}$ detection based on acridine orange and aptamer-wrapped gold nanoparticles. J. Mater. Chem. 2012, 22, 11479-11482. [CrossRef]

32. Zhang, J.R.; Huang, W.T.; Xie, W.Y.; Wen, T.; Luo, H.Q.; Li, N.B. Highly sensitive, selective, and rapid fluorescence $\mathrm{Hg}^{2+}$ sensor based on DNA duplexes of poly(dT) and graphene oxide. Analyst 2012, 137, 3300-3305. [CrossRef] [PubMed]

33. Srinivasan, K.; Subramanian, K.; Murugan, K.; Dinakaran, K. Sensitive fluorescence detection of mercury(ii) in aqueous solution by the fluorescence quenching effect of MoS2 with DNA functionalized carbon dots. Analyst 2016, 141, 6344-6352. [CrossRef] [PubMed]

34. Xie, W.Y.; Huang, W.T.; Luo, H.Q.; Li, N.B. CTAB-capped Mn-doped ZnS quantum dots and label-free aptamer for room-temperature phosphorescence detection of mercury ions. Analyst 2012, 137, 4651-4653. [CrossRef] [PubMed]

35. Zhang, J.R.; Huang, W.T.; Zeng, A.L.; Luo, H.Q.; Li, N.B. Ethynyl and pi-stacked thymine-Hg ${ }^{2+}$-thymine base pairs enhanced fluorescence quenching via photoinduced electron transfer and simple and sensitive mercury ion sensing. Biosens. Bioelectron. 2015, 64, 597-604. [CrossRef] [PubMed]

36. Shankar, B.H.; Jayaram, D.T.; Ramaiah, D. A Reversible Dual Mode Chemodosimeter for the Detection of Cyanide Ions in Natural Sources. Chem. Asian J. 2014, 9, 1636-1642. [CrossRef] [PubMed]

37. Li, N.; Li, Y.H.; Han, Y.Y.; Pan, W.; Zhang, T.T.; Tang, B. A Highly Selective and Instantaneous Nanoprobe for Detection and Imaging of Ascorbic Acid in Living Cells and in Vivo. Anal. Chem. 2014, 86, 3924-3930. [CrossRef] [PubMed]

38. Cen, Y.; Yang, Y.; Yu, R.Q.; Chen, T.T.; Chu, X. A cobalt oxyhydroxide nanoflake-based nanoprobe for the sensitive fluorescence detection of T4 polynucleotide kinase activity and inhibition. Nanoscale 2016, 8 , 8202-8209. [CrossRef] [PubMed] 
39. Chang, Y.Q.; Zhang, Z.; Liu, H.Q.; Wang, N.; Tang, J.L. Cobalt oxyhydroxide nanoflake based fluorescence sensing platform for label-free detection of DNA. Analyst 2016, 141, 4719-4724. [CrossRef]

40. Miyake, Y.; Togashi, H.; Tashiro, M.; Yamaguchi, H.; Oda, S.; Kudo, M.; Tanaka, Y.; Kondo, Y.; Sawa, R.; Fujimoto, T.; et al. MercuryII-Mediated Formation of Thymine-HgII-Thymine Base Pairs in DNA Duplexes. J. Am. Chem. Soc. 2006, 128, 2172-2173. [CrossRef]

41. Chang, E.L.; Simmers, C.; Knight, D.A. Cobalt Complexes as Antiviral and Antibacterial Agents. Pharmaceuticals (Basel) 2010, 3, 1711-1728. [CrossRef]

42. Francisco, T.M.; Gee, W.J.; Shepherd, H.J.; Warren, M.R.; Shultz, D.A.; Raithby, P.R.; Pinheiro, C.B. Hard X-ray-Induced Valence Tautomeric Interconversion in Cobalt-o-Dioxolene Complexes. J. Phys. Chem. Lett. 2017, 8, 4774-4778. [CrossRef] [PubMed]

43. Zhang, X.X.; Zhu, Q.Y.; Lu, J.Y.; Zhang, F.R.; Huang, W.T.; Ding, X.Z.; Xia, L.Q. Boolean logic tree of molecular self-assembly system based on cobalt oxyhydroxide nanoflakes for three-state logic computation, sensing and imaging of pyrophosphate in living cells and in vivo. Analyst 2018. [CrossRef] [PubMed]

44. Wang, J.S.; Liu, J.; Zhang, B.; Cheng, F.; Ruan, Y.J.; Ji, X.; Xu, K.; Chen, C.; Miao, L.; Jiang, J.J. Stabilizing the oxygen vacancies and promoting water-oxidation kinetics in cobalt oxides by lower valence-state doping. Nano Energy 2018, 53, 144-151. [CrossRef]

45. Wang, J.W.; Kuo, Y.M. Synthesis of Nanosized Zinc-Doped Cobalt Oxyhydroxide Parties by a Dropping Method and Their Carbon Monoxide Gas Sensing Properties. J. Nanomater. 2013, 136145. [CrossRef]

46. Aoki, S.; Kimura, E. Zinc-nucleic acid interaction. Chem. Rev. 2004, 104, 769-787. [CrossRef] [PubMed]

47. Sander, S.A.; Van Hall, A.K.; Morrow, J.R. $\mathrm{Zn}^{2+}$-Selective Switch of Duplex to Hairpin DNA. Inorg. Chem. 2015, 54, 3084-3086. [CrossRef] [PubMed]

(C) 2018 by the authors. Licensee MDPI, Basel, Switzerland. This article is an open access article distributed under the terms and conditions of the Creative Commons Attribution (CC BY) license (http:/ / creativecommons.org/licenses/by/4.0/). 